\title{
Electrical Conductivity of the Great Lakes
}

\author{
Lorne H. Doherty
}

\section{Contribution from Radio and Electrical Engineering Division, National Research Council, Ottawa, Canada}

\begin{abstract}
(Received June 21, 1963)
A critical examination has been made of the electrical conductivity values assigned, for radio propagation purposes, to the waters of the Great Lakes. Discrepancies between conductivity values measured in the laboratory and those deduced from field strength measurements are shown to have been the result of both experimental error and the use of faulty standard theoretical field strength curves. The latter source of error is the result of error in the standard curves themselves and in the use of a dielectric constant of 15 for overwater propagation. Conductivity values derived from laboratory measurements of water samples are significantly different from those published in conductivity maps. Large seasonal variations in conductivity, approaching a factor of two in some cases, are a significant complicating factor.
\end{abstract}

\section{Introduction}

This investigation arose out of a discrepancy in conductivity values assigned to the Great Lakes: on the one hand, from field strength measurements and, on the other, from laboratory measurements on water samples.

The Telecommunications Branch of Canada's Department of Transport, which is responsible for radio licensing in Canada, desired to establish more accurate values for the conductivity of the Great Lakes. To this end they approached the National Research Council for the use of NRC's Motor Vessel Radel II in conducting field strength measurements on the four Great Lakes which border on Canada. At that time the author of this paper requested that water samples and temperature soundings be taken at a number of points in each of the lakes during the course of the field strength measurements. During the summer of 1959 these measurements were made and the water samples taken.

From the results of these trials a member of the technical staff of the Department of Transport deduced the conductivity of Lakes Superior, Huron, Erie, and Ontario by fitting experimental field strength versus distance curves to a set of theoretical curves published by the Federal Communications Commission and included in the North American Regional Broadcasting Agreement (NARBA). The method used followed that outlined in the Department of Transport Broadcast Specification No. 10. Basically it involves fitting the experimental points to the theoretical curve at a short distance from the transmitter where ground conductivity does not play an important part in determining field strength, and then observing the conductivity associated with the theoretical curve which most closely approximates the experimental points at greater distances. The resulting data have been published by Ireland [1961]. He gave the following conductivity values in millimhos/meter: Lake Superior, 7 ; Lake Huron, 10; Lake Erie, 10; and Lake Ontario, 15.
The author of this paper proceeded with laboratory measurements of the conductivity of the water samples. The conductivity of the water is dependent on temperature, the coefficient being 2.2 percent per degree Celsius. When the laboratory measurements were corrected to the measured temperature of the lakes, the following results were obtained: Lake $\mathrm{Su}$ perior, 7.0; Lake Huron, 18.9; Lake Erie, 28.0; and Lake Ontario, 26.5.

The large discrepancies which existed between these values and those quoted by Ireland [1961] led to a reexamination of the theoretical curves on which the deduced conductivities were based, and to an additional experimental run on Lake Ontario.

\section{Field Strength Calculations}

A comparison was made between field strength calculations derived from three separate sources. For the single case of a dielectric constant $\epsilon=15$, and conductivity $\sigma=15 \mathrm{mmho} / \mathrm{m}$, data were taken from the Federal Communications Commission (FCC) curve drawn for $1000 \mathrm{kc} / \mathrm{s}$. These curves are plotted in terms of millivolts/meter versus distance in miles, with the field strength adjusted to $100 \mathrm{mv} / \mathrm{m}$ at a distance of $1 \mathrm{mi}$. Since the field strength varies as $1 / d$ over a plane, perfectly conducting earth, the field strength quoted in the FCC curves was multiplied by $d$ and normalized to unity at short ranges. The result is a curve of attenuation relative to a plane, perfectly conducting earth. This form of presentation points up the effect of conductivity more clearly. For the same ground parameters and frequency, the attenuation of the field below that of a plane, perfectly conducting earth was also calculated using the curves and method outlined in the Summary Technical Report of the Committee on Propagation, NDRC [1946]. Finally, the same problem was treated as a summation of modes, following Bremmer [1949]. Five modes were summed to provide field strength values accurate from large distances in to about $60 \mathrm{mi}$. The mode numbers were calculated

(N. R. C. No. 7563 ) 


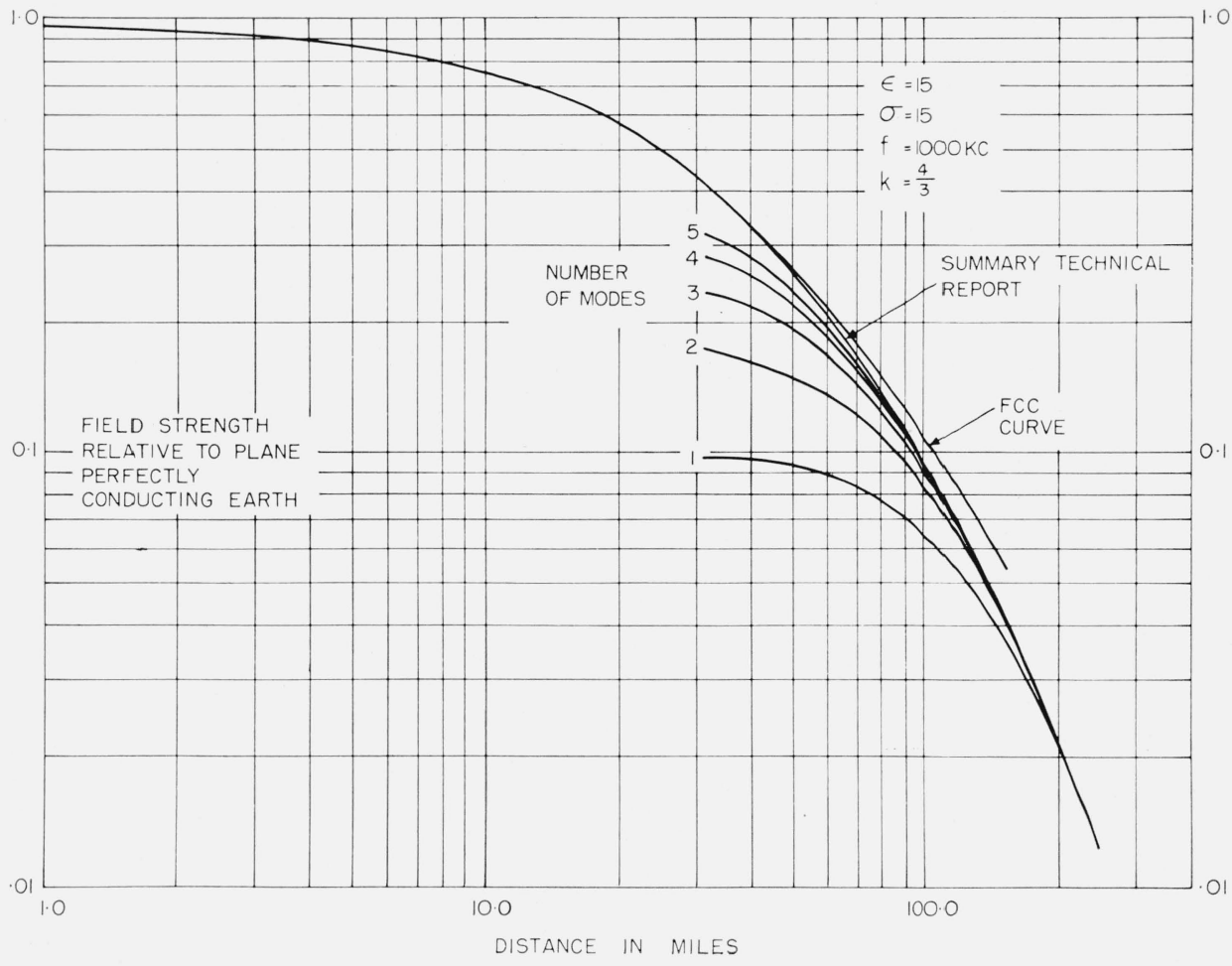

FIGURE 1. Field strength versus distance curves.

From (1) FCC Catalog, (2) Summary Technical Report, (3) Bremmer-summation of five modes.

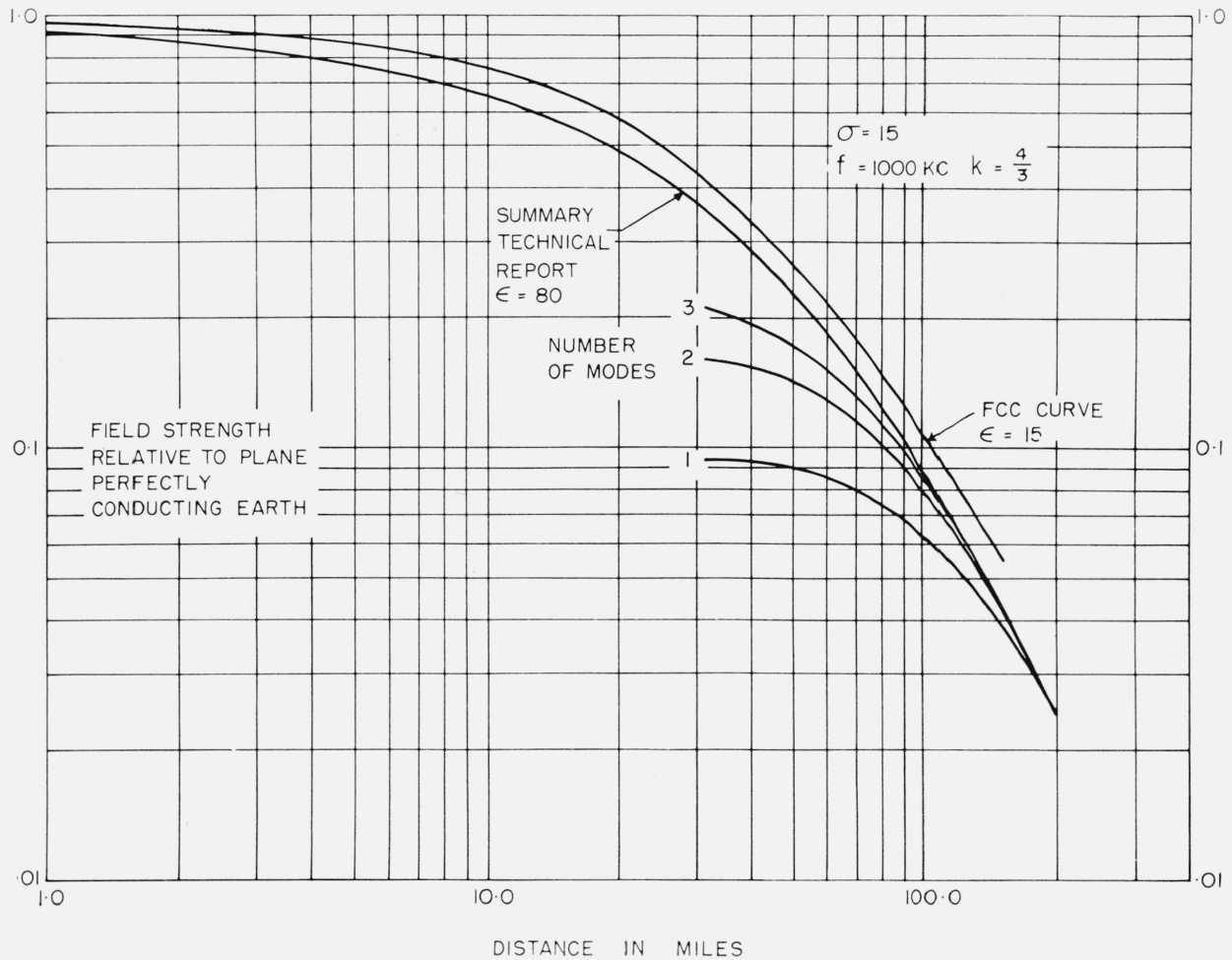

FIgURE 2. Field strength versus distance curves.

From (1) FCC Catalog, $\epsilon=15$, (2) Summary Technical Report, $\epsilon=80$, (3) Bremmer-summation of three modes, $\epsilon=80$. 
from the expressions given in Bremmer's book, but use was made of the more accurate value of the limiting mode number for a flat earth, as given by Norton [1941].

Results of the three derivations of field strength curves are shown in figure 1 . Up to about $20 \mathrm{mi}$ the curves from the Summary Technical Report and the FCC are in close agreement. At distances beyond about $60 \mathrm{mi}$, the Summary Technical Report curve and that from Bremmer's work agree, and it is reasonable to assume, consequently, that the Summary Technical Report method is valid throughout the entire range of distances covered here. The FCC curve, on the other hand, departs steadily from the other curves as distance increases, and is about $2 \mathrm{db}$ high at $150 \mathrm{mi}$.

Curves derived from the Summary Technical Report have also been compared with Bremmer's results for the two cases $\epsilon=80, \sigma=15, f=1000 \mathrm{kc} / \mathrm{s}$, and $\epsilon=80, \sigma=15, f=1200 \mathrm{kc} / \mathrm{s}$. In each case the agreement between the two curves is similar to that shown in figure 1. Consequently, for the comparison in the following section between theoretical and experimental data, the theoretical results from the Summary Technical Report have been used with confidence.

In Ireland's [1961] comparison of experimental data with theoretical curves, he actually used FCC curves for a dielectric constant of 15 , instead of the more appropriate value of 80 for overwater transmission. In figure 2 is shown, for a frequency of $1000 \mathrm{kc} / \mathrm{s}$ - the frequency at which Ireland performed his experiment over three of the four Great Lakesa comparison of the FCC curve for $\epsilon=15, \sigma=15$ and the Summary Technical Report curve for $\epsilon=80, \sigma=$ 15. The difference between the two curves extends to shorter ranges and consequently, if a deduction of conductivity is based on a short experimental run, the conductivity error is likely to be greater. It is obvious that some error must be assigned to Ireland's conductivity values as a result of the use of the inappropriate and inaccurate theoretical curves.

\section{Field Strength Observations on Lake Ontario}

Although some part of the discrepancy between conductivities deduced from field strength measurements and those measured in the laboratory may be assigned to the use of faulty theoretical curves, it is apparent that some additional factor is involved. As a result, field strength measurements were undertaken in June 1961. These were confined to Lake Ontario, and a map of the path taken is shown in figure 3 .

A 150-ft insulated tower was erected at Point Petre at about $500 \mathrm{ft}$ from the shore. Twenty-four radial ground wires, each $800 \mathrm{ft}$ long, were laid on the ground with grounding rods at the ends. A number of western radials were run into the lake. The transmitter delivered a nominal power of $1 \mathrm{kw}$ into this antenna and was operated at $1200 \mathrm{kc} / \mathrm{s}$. Operation of the transmitter was limited to the daylight hours. For the first $3 \mathrm{hr}$ of the run the transmitter was operated continuously, but for the remainder of the run it was turned off for 2 min every half hour for identification and to establish a noise level at the receiver. The transmitter was not modulated.

Receivers were carried aboard the NRC Motor Vessel "Radel II." A 15 -ft whip was mounted on the wooden bridge of the vessel and connected through a matching network to two receivers. One receiver was a Stoddart field strength meter whose output drove an Esterline-Angus recorder. The

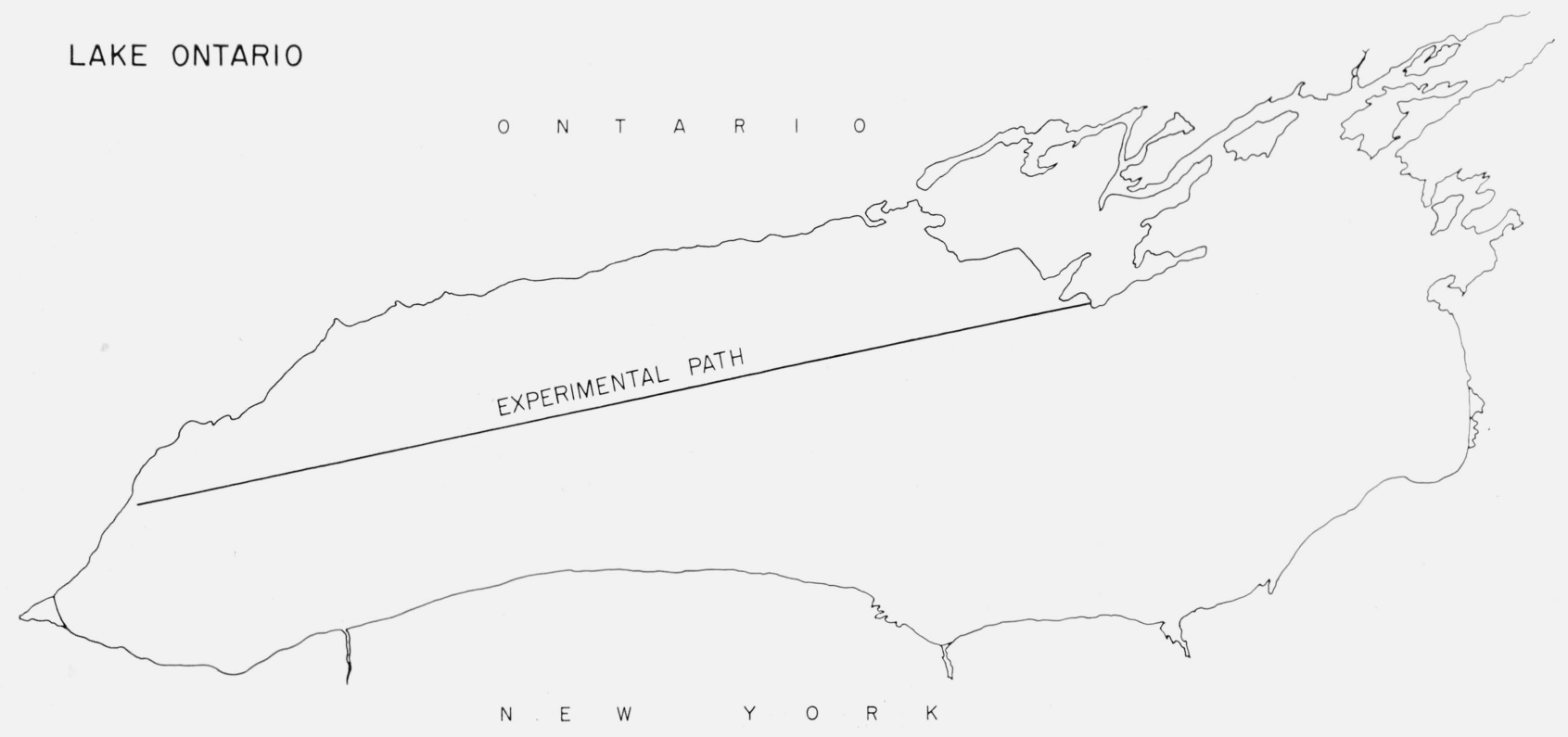

Figure 3. Path of field strength measurements on Lake Ontario 
other receiver had an attenuator at its input and was operated at a constant output level by varying the attenuation at the input. Both receivers were operated from an a-c voltage regulator. A signal generator was available and calibrations were made before and after each run, and spot checks were made on a number of occasions during the runs.

On the first run Radel II was taken to within 1000 $\mathrm{yd}$ of the beach. It then proceeded slowly (5 knots) out along the path shown in figure 3 . After $4 \mathrm{mi}$ the speed was increased to 9 knots, and this was maintained for the remainder of the run. In the early portion of the run, distances from the transmitter were obtained by radar to an accuracy of 25 yd. At about $5 \mathrm{mi}$ from the transmitter, the radar echoes became blurred and uncertain as to exact reflection point. From this point on, distance was determined by dead reckoning until another radar fix was obtained off Toronto. The signal was steady through the first $100 \mathrm{mi}$ of the run. For the last 25 mi, some variation in the recorded signal was observed. This amounted to about $\pm 0.5 \mathrm{db}$. Some, and perhaps all, of this variation was due to interference from the Toronto region and the densely populated area on the northwest shore of the lake. The equipment worked well through this run and the data are believed to be reliable.

After a day's layover in Toronto harbour because of poor weather, a return trip was made over the same course. During the early part of this run much more interference was experienced than on the first run. The variability in recorded signal amounted to about $1.5 \mathrm{db}$. Although the weather was clear, a great deal of this variability was due to thunderstorm atmospherics. At about $90 \mathrm{mi}$ from the transmitter this interference became negligible and was not a factor in the remainder of the run. This run, however, was not as satisfactory as the first. The calibration of the receiving equipment showed evidence of drift-the worst being a 1.5-db change in calibration observed at the end of the run. There was also a temporary failure of the ship's electrical supply during the run. As with the first run, the ship's speed was about 9 knots throughout most of the run, but was cut to about half this value through the $3.5 \mathrm{mi}$ closest to the transmitter. The ship was edged in to a distance of $500 \mathrm{yd}$ offshore, where a measurement was taken and the run terminated.

On both runs it was observed near the transmitter, where the communications receiver was being operated with a large amount of attenuation at the input, that a signal was being received through leakage into the case. As a result the data obtained on the communications receiver have not been used, and the experimental results given here are from the Stoddart record.

A total of nine stops was made during the two runs to collect water samples and to measure water temperatures. The temperature was measured to a depth of $50 \mathrm{ft}$, which was sufficient to determine the position of the thermocline.

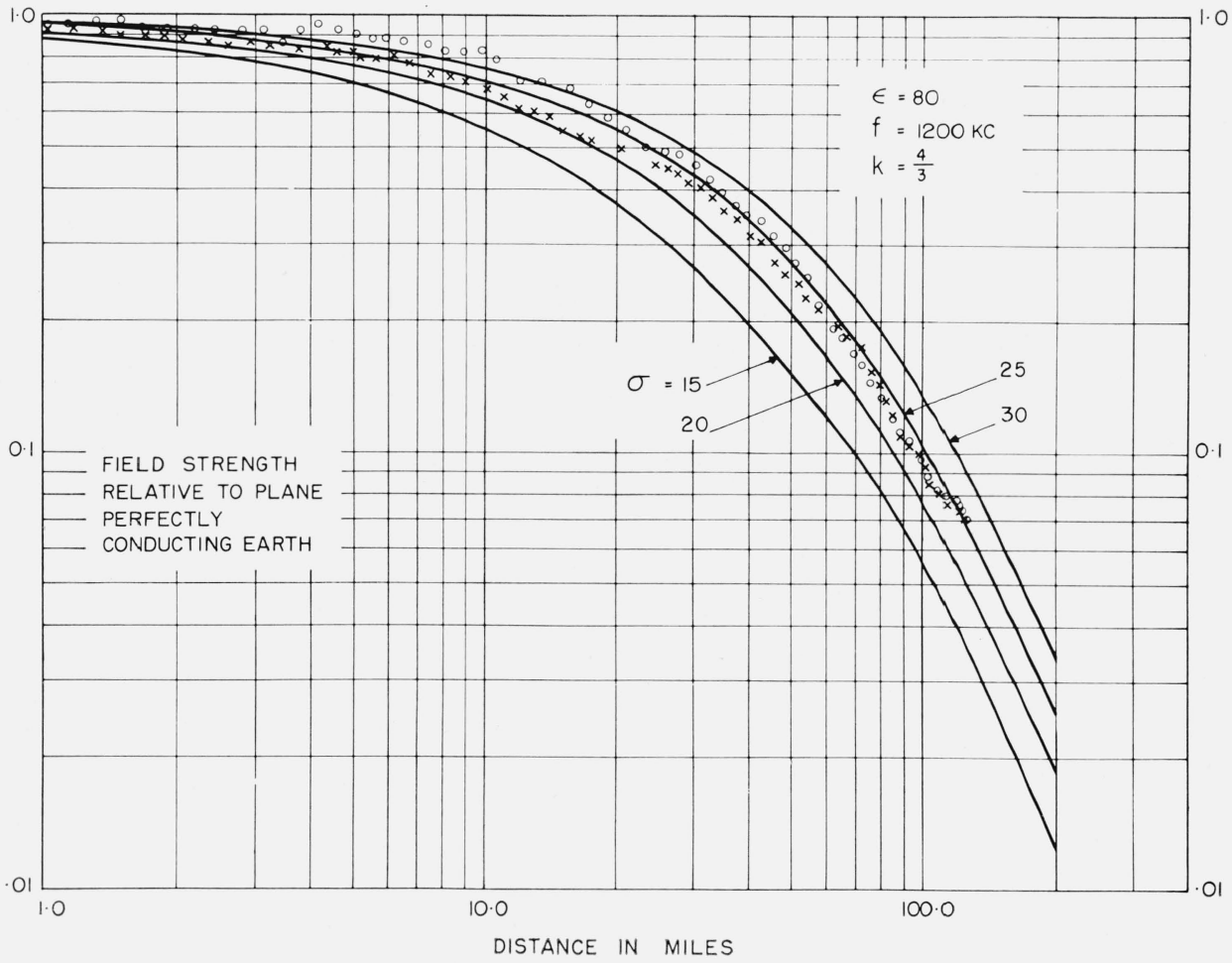

FIgURE 4. Comparison of experimental and theoretical field strength versus distance curves. 


\section{Data Reduction and Observations}

The recorded output of the Stoddart field strength meter was read and was converted to an arbitrary decibel scale using the calibration data taken before and after each run. Small corrections were then applied as indicated by the spot checks of the calibration and tuning performed during the run. In order to convert these data to field strength relative to propagation over a plane perfectly conducting earth, a correction of $20 \log (1 / d)$ was applied to each reading. The readings were then normalized to fit the theoretical curves at ranges in the neighbourhood of one mile. The results are shown plotted in figure 4. The results for the outbound run fit the theoretical curves reasonably well. The points, with a few isolated exceptions, fall between the theoretical curves for conductivities of 20 and 25 $\mathrm{mmho} / \mathrm{m}$.

The curve for the inbound run is much less satisfactory. The manner in which it has been fitted to the theoretical curve is rather arbitrary since it does not conform in shape to the curve for any conductivity value. As mentioned in the previous section, however, experimental difficulties during this run were such that the results must be discounted.

The possibility was considered that a variation of water temperature with depth might produce a corresponding variation of conductivity sufficient to make a surface value inappropriate. Consequently temperature soundings were taken and the results are shown in figure 5. The first run shows a fairly well-developed isothermal layer from the surface to 25 to $40 \mathrm{ft}$. The temperature in this layer shows a small decrease along the path. There was quite an appreciable change two days later. The iso-
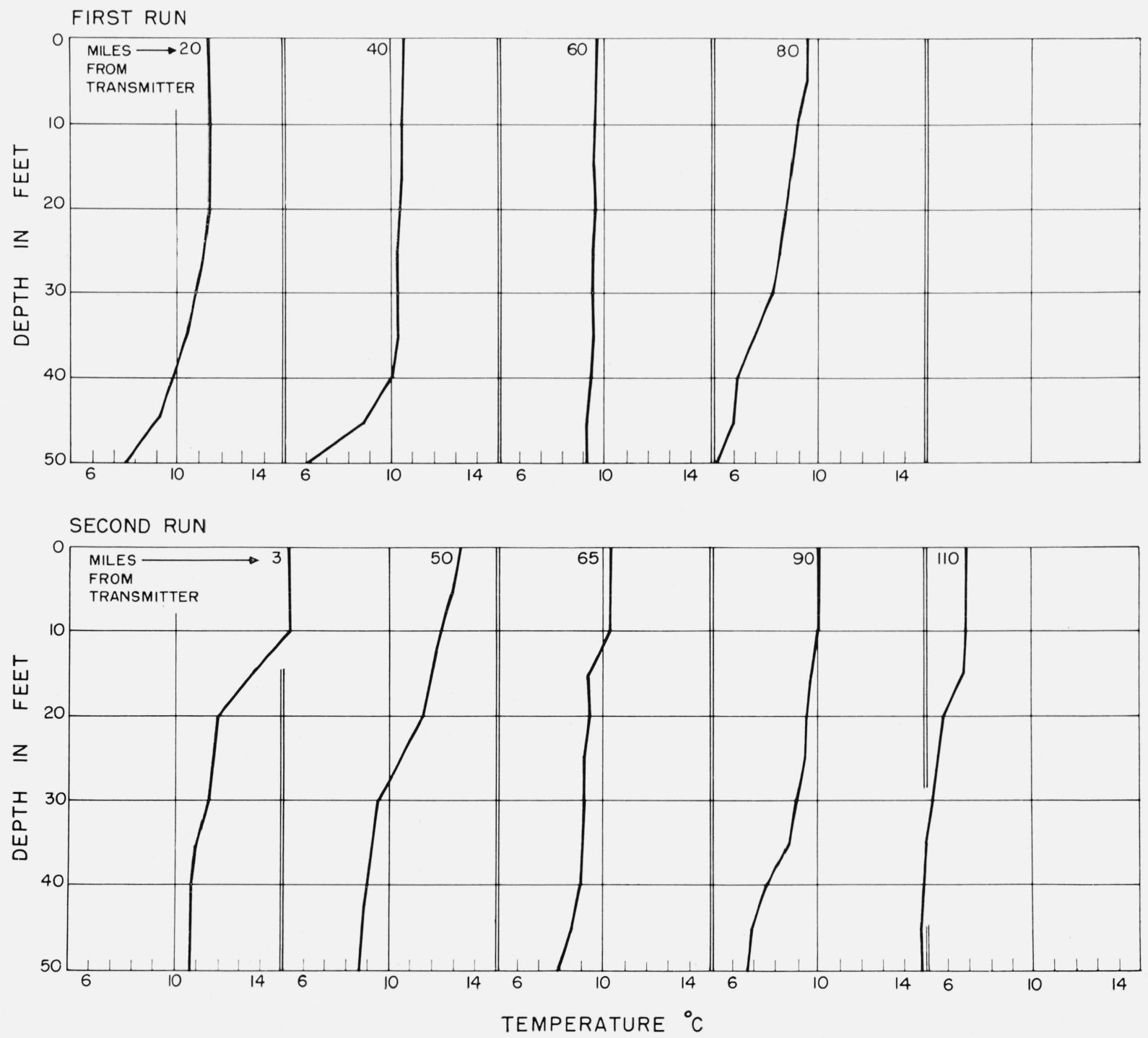

Figure 5. Temperature soundings of Lake Ontario. 
thermal layer was not as well developed and there had been a marked increase in the east-west gradient of surface temperature. Based on laboratory measurements of the temperature dependence of the conductivity, a 20 percent difference in conductivity must have existed between the eastern and western ends of the path on the second run. However, it appears unnecessary to make any allowance for variations along the path or for the variation with depth, and consequently an average value of the temperature is used.

\section{Electrical Conductivity of the Great Lakes From Water Samples}

Water samples were taken from four of the Great Lakes (Superior, Huron, Erie, and Ontario) during the summer of 1959, and samples were taken from Lake Ontario during the summer of 1961. Measurements were made of the electrical conductivity of these samples and the results are shown in table 1 . The measurements were made at room temperature (19 to $22{ }^{\circ} \mathrm{C}$ ) and the results corrected to a common temperature of $21.5^{\circ} \mathrm{C}$. The average surface water temperature of Lake Ontario measured during the field trials described above is listed. The temperatures for the other lakes were measured by Ireland during the field trials leading to his paper of 1961 . The last column of table 1 gives the conductivity

TaвLE 1. Lake conductivities, mmhos $/ m$

\begin{tabular}{|c|c|c|c|c|}
\hline & Ontario & Erie & Huron & Superior \\
\hline $\begin{array}{l}\text { Conductivity at } 21.5^{\circ} \mathrm{Ca} \\
\text { Water temperature, }{ }^{\circ} \mathrm{Cb}^{\mathrm{C}}\end{array}$ & $\begin{array}{l}29.2 \\
10.8\end{array}$ & $\begin{array}{l}26.7 \\
23.7\end{array}$ & $\begin{array}{l}\text { 18. } 2 \\
23.0\end{array}$ & $\begin{array}{r}8.4 \\
14.2\end{array}$ \\
\hline $\begin{array}{l}\text { Conductivity at measured tempera- } \\
\text { ture. }\end{array}$ & 22.3 & 28.0 & 18.8 & 7. 0 \\
\hline
\end{tabular}

a Conductivity of water samples, corrected for temperature of $21.5^{\circ} \mathrm{C}$.

b Temperature of Lake Ontario measured during field trials deseribed in this paper. Temperature of other lakes measured by Ireland, August 1959.

at these measured temperatures which represent the value which would be expected from the field trials. The value of $22 \mathrm{mmho} / \mathrm{m}$ for Lake Ontario is in good agreement with that determined from run 1 described above. The value $7 \mathrm{mmho} / \mathrm{m}$ for Lake Superior is also in agreement with Ireland's value. There is, however, considerable discrepancy for Lake Erie and Lake Huron between these values and the value of $10 \mathrm{mmho} / \mathrm{m}$ for both lakes quoted by Ireland.

The calculated contributions of the various ions to the total conductivity are listed in table 2 . These

TABLE 2. Contribution of the various ions to conductivity $\left(21.5^{\circ} \mathrm{C}\right)$

\begin{tabular}{|c|c|c|c|}
\hline Ion & Erie & Hurcn & Superior \\
\hline 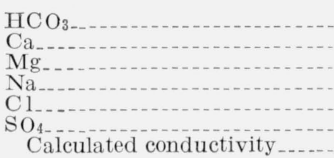 & $\begin{array}{r}5.8 \\
10.1 \\
3.6 \\
1.8 \\
3.9 \\
3.4 \\
28.6\end{array}$ & $\begin{array}{r}4.1 \\
7.3 \\
3.2 \\
0.6 \\
1.2 \\
1.8 \\
18.2\end{array}$ & $\begin{array}{l}2.6 \\
3.8 \\
2.4 \\
0.2 \\
0.2 \\
0.3 \\
9.5\end{array}$ \\
\hline
\end{tabular}

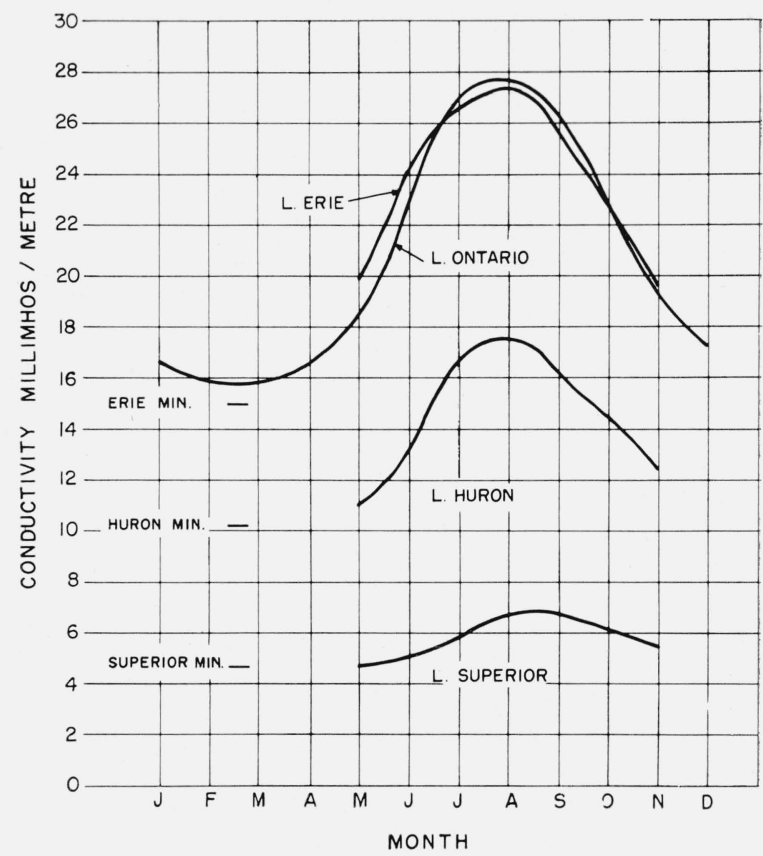

Figure 6. Seasonal variation of conductivity of Lakes Ontario, Erie, Huron, and Superior.

calculated conductivities are in good agreement with the measured values, and show clearly the effect of the change from Pre-Cambrian rock in the drainage area of Lake Superior to the sedimentary rocks around the Lower Lakes. There is no evidence in these figures of industrial pollution affecting the conductivity of the Lower Lakes, as has been suggested [Ireland, 1961].

Laboratory measurements of the dependence of conductivity on water temperature have yielded a relationship

$$
\sigma_{T}{ }^{\circ} \mathrm{C}=\sigma_{20}{ }^{\circ} \mathrm{C}[1+0.022(T-20)] .
$$

Using this relationship, the conductivity of the Great Lakes as a function of the time of year has been calculated. The temperature of the surface water of the Lakes has been taken from a paper by Miller [1952]. There is, of course, a variation in temperature from year to year, but these curves will be indicative of the conductivity change that occurs. Except for Lake Ontario, water temperatures were not quoted for the winter months. However, since the Lakes usually do not freeze, but do approach freezing temperature, a fairly accurate estimate of their minimum temperature may be made. The corresponding minimum value of conductivity is shown in figure 6, together with the plot of conductivity for the months when temperature values are given.

\section{Discussion}

In the process of determining the radiowave conductivity of the waters of the Great Lakes it has been discovered that, in a limited number of cases checked, discrepancies exist between propagation curves 
deduced from the work of Bremmer and those published by the Federal Communications Commission. A better agreement exists between the former and those calculated from the Summary Technical Report. The error is more likely to reside in the FCC curves, but a much more extensive set of calculations would be necessary to determine the extent of the errors.

The electrical conductivity of the waters of Lakes Superior, Huron, Erie, and Ontario has been determined by laboratory measurements of water samples. By measuring radio field strength as a function of distance on Lake Ontario it has been shown that the laboratory-measured conductivity may be applied to the description of radiowave propagation on this lake. By inference the water sample conductivities of the other lakes are believed to be equally valid for radio propagation purposes. Over shallow lakes the penetration of the propagating radiowaves could be sufficient to make the lake bottom a significant factor in an effective conductivity. In the Great Lakes this effect will not be significant at broadcast band frequencies and higher, except near the shore. At $500 \mathrm{kc} / \mathrm{s}$, and taking the lowest conductivity value (March) for each lake, the penetration depths (field $1 / e$ of the surface value) are $30 \mathrm{ft}$ for Lake Superior, $25 \mathrm{ft}$ for Lake Huron, and $20 \mathrm{ft}$ for Lake Erie and Lake Ontario. The penetration depths are, of course, less for higher frequencies and other months of the year. The depths of all the lakes except Lake Erie are very much greater than these penetration depths. The average depth of Lake Erie is about 60 $\mathrm{ft}$, or three times the penetration depth. Thus even for Lake Erie the lake bottom should have no effect on propagation in the broadcast band, although the effect may become noticeable in certain areas of the lake at not much lower frequencies.

The conductivities of Lakes Huron, Erie, and Ontario, as stated in this paper, are significantly different from those recorded in the radio literature [Fine, 1954, and Ireland, 1961]. In addition, the variation of conductivity with temperature and consequently with time of year is considerable. The variation is such that for a $100-\mathrm{mi}$ path on Lake Ontario the field strength of a $1 \mathrm{Mc} / \mathrm{s}$ signal will be $7 \mathrm{db}$ higher at the maximum in August than that at the minimum in March. Although the conductivity values given in this paper differ from those published in radio conductivity maps, they are in accord with values well known to geologists. D. V. Anderson, Department of Geological Sciences, University of Toronto, lists almost identical conductivities in a private communication [1960], and similar values are given in a report by Thomas [1954].

In the calculations of field strength the effect of the atmosphere was included through the use of the effective earth's radius, $k=4 / 3$. The effect of the atmosphere is very small, however, as may be seen by considering the shadow factor-the factor by which the field strength is reduced due to the earth's curvature. Thus over water with a conductivity of $20 \mathrm{mmhos} / \mathrm{m}$ the shadow factor is 0.80 at 100 miles when $k=4 / 3$, and is equal to 0.74 when $k=1$. Therefore the difference between the assumed atmosphere and a homogeneous atmosphere under these conditions is only $0.7 \mathrm{db}$. The accuracy of the measurements was obviously not sufficient to distinguish between the standard atmosphere of $k=4 / 3$ and any other reasonable atmospheric gradient.

The author expresses his thanks to Captain J. A. Hehir and the crew of the Radel II for their cooperation, to Drs. A. G. Mungall and D. Morris for their assistance in the laboratory measurements of conductivity, and to A. Desaulniers for his chemical analysis of the water samples.

An acknowledgement is also due the Commanding Officer, Point Petre Army Camp for his assistance and to Mr. Paul Johnson of the Canadian Broad. casting Corporation for the loan of a portable transmitter.

Mssrs. J. Hazell, A. W. G. Johnson, and D. Rocheleau capably assisted with the experimental part of the program, and Mrs. J. Burrell performed the numerous calculations involved.

\section{References}

Anderson, D. V. (1960), private communication.

Bremmer, H. (1949), Terrestrial Radio Waves (Elsevier Publ. Co., Inc., New York, N.Y.).

Cole, R. H., and Gross, P. M. (1949), A wide range capacitance-conductance bridge, Rev. Sci. Instr. 20, 252-260.

Fine, H. (1954), An effective ground conductivity map for continental United States, Proc. IRE 42, 1405-1408.

Ireland, G. C. (1961), A provisional ground conductivity map for Canada, Proc. IRE 49, 1674-1678.

Kaye, G. W. C., and Laby, T. H. (1956), Tables of Physical and Chemical Constants - 11th ed. (Longmans, Green and Co., London).

Miller, F. Graham (1952), Surface temperature of the Great Lakes, J. Fisheries Res. Board Can. 9, 329-376.

Norton, K. A. (1941), The calculation of ground-wave field intensity over a finitely conducting spherical earth, Proc. IRE 29, 623-639.

Summary Technical Report of the Committee on Propagation NDRC, Washington, D.C. (1946), Vol. 3: The propagation of radio waves through the standard atmosphere, ed. Stephen S. Attwood.

Thomas, J. F. J. (1954), Water Survey Rept. No. 3, Dept. Mines and Tech. Surveys Bull. 837 (Queen's Printer and Controller of Stationery, Ottawa, Canada).

(Paper 67D6-306) 


\title{
Publications of the Staff of the National Bureau of Standards*
}

\author{
Selected Abstracts
}

Quarterly radio noise data-June, July, August 1962, W. Q. Crichlow, R. T. Disney, and M. A. Jenkins, NBS Tech. Note 18-15 (Mar. 1963), 45 cents.

Radio noise measurements are being made at sixteen stations in a worldwide network supervised by the National Bureau of Standards. The results of these measurements for the period June, July, August 1962 are presented. These are based on three parameters of the noise: (1) the mean power, (2) the mean envelope voltage, and (3) the mean logarithm of the envelope voltage. The mean power averaged over a period of several minutes is the basic parameter and is expressed as an effective antenna noise figure, $F_{a} . \quad F_{a}$ is defined as the noise power available from an equivalent lossless antenna in $\mathrm{db}$ above $k t b$ (the thermal noise power available from a passive resistance) where

$k=$ Boltzman's constant $\left(1.38 \times 10^{-23}\right.$ joules per degree Kelvin) $t=$ Absolute room temperature (taken as $288^{\circ} \mathrm{K}$ )

$b=$ bandwith in cycles per second.

The mean voltage and mean logarithm are expressed as deviations, $V_{d}$ and $L_{d}$, respectively, in $\mathrm{db}$ below the mean power.

Measurements of these parameters were made with the $\mathrm{Na}$ tional Bureau of Standards Radio Noise Recorder, Model ARN-2, which has an effective noise bandwidth of about $200 \mathrm{c} / \mathrm{s}$ and uses a standard $21.75 \mathrm{ft}$ vertical antenna. A fifteen-minute recording is made on each of eight frequencies two at a time during each hour, and these fifteen-minute samples are taken as representing the noise conditions for the full hour. The month-hour medians, $F_{a m}, V_{d m}$, and $L_{d m}$, are determined from these hourly values for each of the corresponding parameters. Normally from twenty-five to thirty observations of the mean power are obtained monthly for each hour of the day, and from ten to fifteen observations of the voltage and logarithm deviations. When there are fewer than fifteen observations of the mean power, or seven observations of the voltage and logarithm deviations, the tabulated values are identified by an asterisk.

Mean electron density variations of the quiet ionosphere, No. 9-November 1959, J. W. Wright, L. R. Wescott, and D. J. Brown, NBS Tech. Note 40-9 (Apr. 1963). 35 cents.

The CRPL has initiated a program for large-scale computation of electron density profiles from ionospheric vertical soundings. Scaling is performed at field stations, permitting computation of hourly profiles at the Central Laboratory. These profiles are combined to form hourly mean quiet profiles for each station and month. The results of this program for the month of November are illustrated graphically. This report is the ninth of a series illustrating the electron density variations in the mean quiet ionosphere between latitudes $15^{\circ} \mathrm{N}$ and $50^{\circ} \mathrm{N}$ along the $75^{\circ} \mathrm{W}$ meridian.

Mean electron density variations of the quiet ionosphere, No. 10 -December 1959, J. W. Wright, L. R. Wescott, and D. J. Brown, NBS Tech. Note 40-10 (Mar. 1963), 35 cents.

The CRPL has initiated a program for large-scale computation of electron density profiles from ionospheric vertical soundings. Scaling is performed at field stations, permitting computation of hourly profiles at the Central Laboratory. These profiles are combined to form hourly mean quiet profiles for each station and month. The results of this program for the month of December are illustrated graphically. This report is the tenth of a series illustrating the electron density variations in the mean quiet ionosphere between latitudes $15^{\circ} \mathrm{N}$ and $50^{\circ} \mathrm{N}$ along the $75^{\circ} \mathrm{W}$ meridian.
Equipment characteristics and their relation to system performance for tropospheric communication circuits, A. F. Barghausen, F. O. Guiraud, R. E. McGavin, S. Murahata, and R. W. Wilber, NBS Tech. Note 103 (Jan. 1963), \$1.00.

The performance of a tropospheric communications system, either within the line of sight or beyond the line of sight, is directly dependent on the operating characteristics of the equipment.

Performance predictions of a communications system are made on the basis that equipment will operate in a prescribed manner. The degree of success of the communications system will depend largely upon how well these predicted values correspond to the actual operating values.

Consideration is given to those portions of the equipment that have definite effect upon the operating performance. Specific items of equipment and methods for determining their performance are considered. Representative results in light of the present state of the art permits an evaluation of an actual system in terms of realizing an "optimum" system. In systems that do not have the "optimum" characteristics desired, consideration is given to laboratory devices which may alleviate these deficiencies. Future systems should consider incorporating these devices as development permits.

Atlas of Fourier coefficients of diurnal variation of $\boldsymbol{f}_{0} \boldsymbol{F}_{2}$, William B. Jones, NBS Tech. Note 142 (A pr. 1962), \$2.50.

A series of graphical representations is given for illustrating the regular and continuous geographic variations of Fourier coefficients $a_{j}$ and $b_{j}$ obtained from the diurnal analysis of $f_{0} F_{2}$ monthly medians, including their main latitudinal trend, mixed latitudinal and longitudinal variation, and the effect due to noise (random fluctuation in the original data). To illustrate the systematic changes in these variations with seasons and with solar activity, corresponding graphs are given for four seasonal months for minimum and maximum years of solar activity (1954 and 1958).

On plasma collision frequencies proportional to energy in the radio wave reflection and transmission process, J. R. Johler and John D. Harper, Jr., NBS Tech. Note 164 (Mar. 1963), 40 cents.

The high conductivity of the ionosphere in large measure determines the propagation of terrestrial radio waves. The ionosphere can be treated theoretically as a magneto-ionic plasma composed of electrons, ions, and neutral particles. Certain macroscopic properties of these particles, such as the complex index of refraction, can be deduced from the microscopic particle statistics of ionized gases. These properties can then be applied directly to Maxwell's equations to determine the reflection and transmission process, provided a suitable composition for the model plasma has been found.

The composition of the real ionosphere is not uniform, especially in the vertical direction. Such nonuniformity can be treated theoretically with the aid of a flexible model ionosphere employing the notion of a continuously stratified plasma.

An extensive survey of both the index of refraction of typical electron-ion plasmas as models of the ionosphere together with the reflection coefficients is made in this paper to determine the significance of the notion of heavy-particle electron-collision frequencies proportional to energy.

The introduction of electron-ion collision frequencies with a linear dependence upon the average value of the Maxwellian particle velocity distribution results in some interesting changes in the detail of the reflection and transmission 
coefficients at low frequencies. It can be noted, however, that the reflection coefficients determined by application of the continuously stratified notion to particular models of the ionosphere are not drastically changed by the introduction of such electron collisions.

An atlas of whistlers and VLF emissions. A survey of VLF spectra from Boulder, Colorado, D. L. Jones, R. M. Gallet, J. M. Watts, and D. N. Frazer, NBS Tech. Note 166 (PB 181454) (Jan. 1963), \$2.25.*

Naturally occurring VLF noises are classified and spectrograms illustrating each class are presented.

The report is divided into six sections. The first section consists of the systematic classification of VLF noises. Samples of whistlers and VLF emissions are shown in the second and third sections, respectively. The next section gives examples of interactions between these two classes. Section five consists of some exceptionally active periods during magnetic disturbances. The last section is a synoptic survey for the four months, March through June, 1957. A spectrogram is given for every observation period containing any VLF activity.

Most of the data were recorded at the Sunset Field Station of the National Bureau of Standards, Boulder, Colorado, during 1956-1957.

Profiles of electron density over the magnetic equator obtained using the incoherent scatter technique, K. L. Bowles, NBS Tech. Note 169 (Mar. 1963), 25 cents.

The technique of electron density measurement by incoherent scatter, using a high powered radar, has now been thoroughly explored in the literature. A representative bibliography on the subject, as well as a summary of experimental aspects, current early in 1962, has been given by Bowles, Ochs, and Green [1962]. The object of this note is to present a number of profiles obtained using incoherent scatter near Lima, Peru.

Practical methods for calibration of potentiometers, D. Ramaley, NBS Tech. Note 172 (Mar. 1963), 30 cents. Potentiometer circuitry, particularly as related to calibration, is discussed with the primary consideration given to the required circuit measurements. The more feasible means of calibrating potentiometers are described in considerable detail. Emphasis is placed upon the use of the Universal Ratio Set as the basic implement for accomplishing the major portion of potentiometer calibrations.

Curves of ground proximity loss for dipole antennas, L. E Vogler and J. L. Noble, NBS Tech. Note 175 (May 1963), 30 cents.

Ground proximity loss, defined as the decibel ratio of antenna input resistance to its free space resistance, is presented in graphical form for four types of antennas: vertical and horizontal electric and magnetic elementary dipoles. Assuming a non-layered ground characterized throughout by a relative dielectric constance $\epsilon_{\mathrm{r}}$ and conductivity $\sigma$, curves are given showing the ground proximity loss for a wide range of values of ground constants, antenna height above the ground surface, and frequency.

Instability of the equatorial $F$ layer after sunset, W. Calvert, J. Geophys. Res. 68, 2591-2593, (May 1, 1963).

It is shown that the downward wind caused by the cooling of the upper atmosphere after sunset could give rise to the irregularities in the equatorial $F$ region observed at that time. The observed cooling appears to provide the same degree of instability as that provided by electric fields on Martyn's theory.

Effects of the nuclear explosion over Johnston Island observed in Peru on July 9, 1962, R. Cohen, M. Casaverde, and A. Giesecke, J. Geophys. Res. 68, 2603-2611 (May 1, 1963).

An account is given of observations in Peru associated with the nuclear explosion over Johnston Island on July 9, 1962. The observations discussed are principally those of magnetic and micropulsation activity resulting from the ELF and hydromagnetic waves accompanying the explosion.

*Available by purchase from Office of Technical Services, U.S. Dept. of Commerce, Washington D.C., 20402; order by PB number.
The association of plane-wave electron-density irregularities with the equatorial electrojet, $R$. Cohen and K. L. Bowles, J. Geophys. Res. 68, 2503-2525 (May 1, 1963).

The field-aligned irregularities responsible for the "equatorial sporadic $E$ " configuration on equatorial ionograms have been been established to be plane waves of electron density aligned with the magnetic field but moving perpendicularly to it. It has been generally realized that there is some connection between these irregularities and the equatorial electrojet. This paper demonstrates that the irregularities are spatially and temporally correlated with the equatorial electrojet. First, it is shown experimentally that the irregularities occur in the height and latitude region in which the electrojet flows; i.e., they are embedded in the electrojet. Second, it is shown that there are temporal correlations between the intensity of radio waves scattered from the irregularities associated with the electrojet and the horizontal intensity of the earth's magnetic field, a measure of the electro et current. The scattered intensity is imperceptible until a certain "threshold" of electrojet current is reached. As the electrojet current increases above the threshold, a scatter signal suddenly rises above the noise, increasing abruptly at first, then gradually. This threshold suggests that the plasma wave irregularities are generated by the current stream. According to the theory of Farley such a threshold can be interpreted as the onset of a plasma instability in the equatorial electrojet, leading to the formation of plasma waves. It is shown that by means of the intensity of the signal scattered from the electrojet irregularities, together with magnetometer measurements, it may be possible to estimate from ground observations the daytime field variation resulting from disturbance currents at great distances from the earth.

Field-aligned $\boldsymbol{E}$-region irregularities identified with acoustic plasma waves, K. L. Bowles, B. B. Balsley, and R. Cohen, J. Geophys. Res. 68, 2485-2501 (May 1, 1963).

This paper described some measurements related to the nature of field-aligned irregularities in the $E$ region. The measurements were performed near the magnetic equator, and the irregularities are attributed to the equatorial electrojet. It is shown that the irregularities are most likely to consist of plane acoustic waves generated by an instability resulting from the flow of current in the electrojet. Reference is made to a recent theory of Farley in which the existence of such waves is predicted. The characteristics of auroral radar echoes are shown to be similar to those of the equatorial echoes. It is inferred that the auroral field-aligned irregularities are also caused by the flow of electrojets.

Distribution of latitude of red arcs, E. Marovich and F. E. Roach, J. Geophys. Res. 68, 1885-1888 (A pr. 1, 1963).

Red (6300 A) auroral ares were observed during twenty-three nights at Rapid City, South Dakota, for the 1957-1958 IGY period. It is shown that they are strongly concentrated at an invariant latitude of $53^{\circ}$ (sheet parameter $L=3$ ), whereas visual auroral features occur predominantly at an invariant latitude of $67^{\circ}(L=6.5)$.

International symposium on equatorial aeronomy: Introduction, R. Cohen, J. Geophys. Res. 68, 2359-2361 (May 1, 1963). Papers selected were from among those presented at the first International Symposium on Equatorial Aeronomy, held at Hotel Huaychulo, near Huancayo, Peru, from September 18 through 25, 1962. A summary session was held in Lima on the morning of September 27, 1962.

The field now known as "equatorial aeronomy," refers to studies of the atmosphere in the vicinity of the magnetic equator. In particular, inasmuch as charged particles interact with the earth's magnetic lines of force, the geometry of the equatorial magnetic field leads to many interesting ionospheric and magnetic phenomena. Many workers all over the world have been studying the equatorial ionosphere for some time. Although considerable information has been accumulated, many mysteries still remain. However, there had never been a conference devoted exclusively to equatorial aeronomy (as there had been for polar aeronomy, for example). The need for such a conference was recognized in 1959, and this symposium was held three vears later.

The objectives of the meeting were threefold: (1) to arrive at an understanding of what was known in each area of the field 
of equatorial aeronomy, (2) to decide what important problems were still outstanding in each area, and (3) to propose individual and collective programs for solving some of these problems and filling gaps in the present knowledge.

Equatorial ionospheric variations during geomagnetic storms, S. Matsushita, J. Geophys. Res. 68, 2595-2601 (May 1, 1963). During geomagnetic storms, ionospheric Dst variations in the magnetic equatorial zone and low latitudes seem to be characterized by an increase of the maximum electron density of the $F_{2}$ layer. This increase is confirmed by the electron density profile data. Possible causes of the increase are discussed.

Characteristics of spread $\boldsymbol{F}$ at high geomagnetic latitude, W. K. Klemperer, J. Geophys. Res. 68, No. 10, 3191-3196 (May 15, 1963).

A detailed analysis of the fading observed during spread $F$ at Ithaca, New York $\left(74^{\circ}\right.$ dip), shows that steady components are present at all ranges within the echo proper. Accordingly, it seems unlikely that theories relying on random scattering processes can properly explain the pronounced spread in range observed. To investigate the mechanism reponsible for spread $F$, a lobe-swept interferometer was designed to estimate the width of the angular spectrum of radio waves reflected from the ionosphere under spread- $F$ conditions. This instrument was operated at spacings from $5^{1 / 2}$ to $12^{1 / 2}$ wavelengths. Data obtained with it indicate that the type of spread $F$ observed at high geomagnetic latitudes has a narrow angular spectrum. These observations are in substantial agreement with recent theories that attribute long delay times to the guiding action of field-aligned irregularities within the $F$ layer. The correlation of spread $F$ (as observed on an ionospheric sounder at Ithaca) with strong scintillation of the radio source Cygnus A at upper culmination is found to exceed 0.8. The height of the irregularities responsible for radiostar scintillation is not known accurately; there are indications, however, that the irregularities lie above the $F$-laver maximum, and it is tempting to imagine them extending right through the $F$ region on nights of spread- $F$ activity.

The lifetime and movement of artificially produced electron clouds observed with spaced ionosondes, J. W. Wright, $J$. Geophys. Res. 68, No. 10,3011-3020 (May 15, 1963).

Observations of electron clouds in the 1960 Firefly Series, made with four closely-spaced ionospheric sounders, are described. Movements of the clouds as deduced by these radio means correspond closely to those observed optically throughout the period when such observation was possible. Cloud lifetimes sometimes exceeded two hours under sunlit conditions but were much shorter in the absence of ionizing radiation. In either case, the cloud echoes resemble those from sporadic $E$, but the relationship between the two phenomena is puzzling. Evidence is given for a height-gradient of drift velocity in the altitude range 95 to $115 \mathrm{~km}$. A correspondence is noted between the cloud drift velocity pattern and the wind system calculated from geomagnetic data by the dynamo theory of the $S_{\mathrm{Q}}$ current system.

Millimeter wavelength resonant structures, R. W. Zimmerer, M. V. Anderson, G. L. Strine, and Y. Beers, IEEE Trans. Microwave Theory Tech. MTT-11, No. 2, 142-149 (Mar. 1963).

This paper discusses the construction millimeter wave FabryPerot resonators, using both planer and spherical reflectors. It also discusses the equivalent circuits of planar reflectors and the method of obtaining efficient power transfer into the resonators.

Leaf temperature and energy exchange, D. M. Gates, Arch. Meteorol. Geophys. Bioklimatol., Ser. B, 12, 321-336 (1963)

Leaf temperatures were measured by means of an infrared radiometer. Sunlit leaves were as much as $20^{\circ} \mathrm{C}$ above air temperature. Shade leaves averaged $1.5^{\circ} \mathrm{C}$ below air temperature during the daytime. Quantitative calculations of the energy exchange for a leaf are made showing the distribution of energy into solar and thermal radiation, reradiation by the leaf, convection exchange, and transpiration. From the observed temperatures it is shown that transpiration must play a relatively strong role in reducing leaf temperatures, and that convection is a relatively inefficient process
The ionosphere over Antarctica, W. R. Piggott and A. H Shapley, Antarctic Research, Geophys. Mono. 7 (1962).

The $F_{2}$ layer over Antarctica is influenced by factors which vary with Universal Time. The ionization density inside the auroral zone in winter mainly depends on these factors but their influence is also detectable outside this region. The time when the layer is lowest is also approximately constant in UT. Similar behavior can be detected over an even wider area in summer. The changeover from winter- to summertype diurnal variations occurs very suddenly at certain stations but the date of change varies with station position. Studies of $f_{0} F_{1}$ at constant solar zenith angle show that changes comparable with the solar cycle variation occur with dip angle, magnetic activity and the separation of the $F_{1}$ and $F_{2}$ layers. Some studies of polar cap absorption (PCA) events using Antarctic $f_{\mathrm{min}}$ data are described and a list of PCAs detected in Antarctica is given.

The measurement of characteristics of terrestrial radio noise, W. Q. Crichlow, URSI Special Report No. 7 (Elsevier Publ. Co., Amsterdam, 1962)

A resume is presented of recent measurements in the field of terrestrial radio noise. Particular emphasis is given to the various types of measurements and their significance in determining the influence of the noise on the reception of signals.

It is recommended that the noise power be the basic reference for the noise level and that measurements of this parameter be made at as many locations as possible throughout the world. It is further recommended that detailed statistical characteristics be studied at selected locations.

Measurement techniques are also described in such a way as to insure uniformity in data obtained by different observers.

Two-stream plasma instability as a source of irregularities in the ionosphere, D. T. Farley, Jr., Phys. Rev. Letters 10, 279-282 (Apr. 1963)

The purpose of this note is to describe an extension of the theory of the two-stream plasma ion wave instability and an application of the theory in the physies of the ionosphere We shall include in the theory the effect of a magnetic field and also the effect of collisions with neutral particles. Both of these effects can be important in the ionosphere. We find that the qualitative and quantitative predictions of the theory are in agreement with the observed characteristics of a certain type of irregularity found in the equatorial ionosphere. These are often referred to as "equatorial sporadicE" irregularities. Similar irregularities often appear in the polar ionosphere during auroral displays; it seems very likely that these too are caused by the two-stream instability.

The total electron content of the ionosphere at middle latitudes near the peak of the solar cycle, R. S. Lawrence, D. Jane Posakony, O. K. Garriott, and S. C. Hall, Geophys. Res. 68, 1889-1898 (A pr. 1, 1963).

The electron content of the ionosphere during the period September 1958 to December 1959 has been calculated from observations of the Faraday rotation of the signals from Sputnik 3 recorded at Boulder and Stanford. Diurnal and seasonal effects are pronounced, and from these measurement. we deduce daytime temperatures of $1500^{\circ} \mathrm{K}$ in winter and nearly $2000^{\circ} \mathrm{K}$ in summer, with a diurnal variation of at least $330^{\circ} \mathrm{K}$ and very likely as much as $500^{\circ} \mathrm{K}$. During magnetic storms, a reduction in total electron content and an increase in scale height are found to accompany the usual decrease in maximum electron density.

Some causes of resonant frequency shifts in atomic beam machines. I. Shifts due to other frequencies of excitation, J. H. Shirley, J. Appl. Phys. 34, 783-788 (A pr. 1963).

The quantum theory of an atomic beam machine is set up in matrix form. A new method is then used to derive the Bloch-Siegert shift in the resonance. The results are extended to the case of Ramsey-type excitation. Finally the Bloch Siegert shift is computed for the present atomic beam frequency standards and found to be well below the accuracy of measurement.

Some causes of resonant frequency shifts in atomic beam machines. II. The effect of slow frequency modulation on the Ramsey line shape, J. H. Shirley, J. Appl. Phys. 34, 789-791 (Apr. 1963). 
The effect of slow frequency modulation of the exciting radiation on the Ramsey line shape observed in an atomic beam experiment is formulated theoretically. It is shown that the presence of second harmonic in the modulation can introduce measureable frequency shifts, whether observed directly or with a servo system.

Energy environment in which we live, D. M. Gates, $A m$. Scientist 51, No. 3, 327-348 (Sept. 1963).

Climates are described in terms of the radiant heat load on a plant or animal and not just in meteorological terminology with parameters such as air temperature, relative humidity, precipitation, wind, etc. The mechanisms for dissipating a heat load on a plant or animal are described, namely reradiation and convection. The phenomena of free and forced convection from plants is demonstrated by means of schlieren photography. From a detailed analysis of the energy budget of a plant the diurnal temperature cycle of the plant is described. The temperature of a plant then determines certain chemical rate processes within the plant tissue which in turn define temperature regimes which are favorable or unfavorable to plant growth and response.

\section{Other NBS Publications}

\section{J. Res. NBS 67A (Phys. and Chem.), No. 5 (Sept.-Oct. 1963),} 70 cents.

Reduction of space groups to subgroups by homogeneous strain. H. S. Peiser, J. B. Wachtman, Jr., and R. W. Dickson.

High-temperature thermodynamic functions for zirconium and unsaturated zirconium hydrides. T. B. Douglas

Heat of oxidation of aqueous sulfur dioxide with gaseous chlorine. W. H. Johnson and John R. Ambrose.

Thickness of adsorbed polystyrene layers by ellipsometry. R. R. Stromberg, E. Passaglia, and D. J. Tutas.

Melting temperature and change of lamellar thickness with time for bulk polyethylene. J. J. Weeks.

Precise coulometric titrations of potassium dichromate. G. Marinenko and J. K. Taylor.

Resolution limts of analyzers and oscillatory systems. E. L. R. Corliss.

Synthesis, purification, and physical properties of seven twelve-carbon hydrocarbons. T. W. Mears, C. L. Stanley, E. L. Compere, Jr., and F. L. Howard.

Reactions of polyfluorobenzenes with nucleophilic reagents. L. A. Wall, W. J. Pummer, J. E. Fearn, and J. M. Antonucci.

J. Res. NBS 67B (Math. and Math. Phys.), No. 3 (July-Sept. $1963), 75$ cents.

Remarks on hypo-elasticity. C. Truesdell.

Error bounds in the pointwise approximation of solutions of elastic plate problems. J. H. Bramble and L. E. Payne.

Effect of error in measurement of elastic constants on the solutions of problems in classical elasticity. J. H. Bramble and L. E. Payne.

Eigenfunctions of the $f^{3}$ configuration. J. C. Eisenstein Zeros of first derivatives of Bessel functions of the first kind, $J_{n}^{\circ}(x), 21 \leq n \leq 51,0 \leq x \leq 100$. G. W. Morgenthaler and H. Reismann.

Standard X-ray diffraction powder patterns, H. E. Swanson, M. C. Morris, R. P. Stinchfield, and E. H. Evans, NBS Mono. 25, Section 2 (May 3, 1963), 35 cents.

Refractive indices and densities of aqueous solutions of invert sugar, C. F. Snyder and A. T. Hattenburg, NBS Mono. 64 (June 7,1963$), 15$ cents.

Reduction of data for piston gage pressure measurements, J. L. Cross, NBS Mono. 65 (June 17, 1963), 15 cents.

Tabulation of data on receiving tubes, C. P. Marsden and J. K. Moffitt, NBS Handb. 83 (May 23, 1963), \$1.25. (Supersedes Handb. 68.)

Radiobiological dosimetry. Recommendations of the International Commission on Radiological Units and Measurements, NBS Handb. 88 (April 30, 1963), supersedes parts of Handb. 78. Handbooks 84 through 89 will completely replace $\mathrm{H} 78,25$ cents.
Quarterly radio noise data-September, October, November 1962, W. Q. Crichlow, R. T. Disney, and M. A. Jenkins, NBS Tech. Note 18-16 (June 10, 1963), 60 cents.

Phototypesetting of computer output, an example using tabular data, W. R. Bozman, NBS Tech. Note 170 (June 25, 1963), 10 cents.

Table of attenuation error as a function of vane-angle error for rotary vane attenuators, W. Larson, NBS Tech. Note 177 (May 20, 1963), 75 cents.

An interpolation procedure for calculating atmospheric band absorptions from laboratory data, L. Droppleman, L. R. Megill, and R. F. Calfee, NBS Tech. Note 178 (June 3, 1963), 20 cents.

Tabulation of published data on Soviet electron devices, C. P. Marsden, NBS Tech. Note 186 (June 3, 1963), 45 cents.

Tables describing small-sample properties of the mean, median, standard deviation, and other statistics in sampling from various distributions, C. Eisenhart, L. S. Deming, and C. S. Martin, NBS Tech. Note 191 (June 14, 1963), 20 cents.

National standard reference data program, background information, NBS Tech. Note 194 (June 1963), 25 cents.

Nuclear reasonance and the hyperfine field in dilute alloys of nickel in iron, R. L. Streever, L. H. Bennett, R. C. La Force, and G. F. Day, J. Appl. Phys. 34, No. 4, Pt. 2 1050-1051 (Apr. 1963).

The history of Pt. 27, E. Wichers, Book, Temperature, Its Measurement and Control in Science and Industry 3, Pt. 1, 259-262 (Reinhold Publ. Corp., New York, N.Y., 1962).

On the dependence of absorption coefficients upon the area of the absorbent material, E. D. Daniel, J. Acoust. Soc. Am. 35. No. 4, 571-573 (Apr. 1963).

The role of the International Union of pure and applied chemistry, E. Wichers, J. Chem. Doc. 3, No. 7, 7-11 (1963).

New scale of nuclidic masses and atomic weights, E. Wichers, Nature 194, No. 4829, 621-624 (May 19, 1962).

Note on a subgroup of the modular group, M. Newman and J. R. Smart, Proc. Am. Math. Soc. 14, No. 1, 102-104 (Feb. 1963)

Calibration of photogrammetric lenses and cameras at the National Bureau of Standards, F. E. Washer, Photogrammetric Eng. XXIX, No. 1, 113-119 (Jan. 1963).

The orthobaric densities of parahydrogen, derived heats of vaporization and critical constants, H. M. Roder, D. E. Diller, L. A. Weber, and R. D. Goodwin, Cryogenics 3, 16-22 (Mar. 1963).

Melting pressure equation for the hydrogens, R. D. Goodwin, Cryogenics 2, No. 6, 1-3 (Dec. 1962).

Isotopic fractionation of uranium in sandstone, J. N. Rosholt, W. R. Shields, and E. L. Garner, Science 139, 224-226 (Jan. 18, 1963)

Present status of our knowledge of atomic transition probabilities, W. L. Wiese, Proc. Tenth Colloquium Spectroscopic Intern., pp. 37-56 (Univ. of Maryland, College Park, Md., 1962).

Rubber and rubber products, W. P. Tyler and M. Tryon, Book, Industrial and Natural Products and Noninstrumental Methods, 6th ed., Standard Methods of Chemical Analysis 11B, Ch. 43, 2146-2226 (D. Van Nostrand Co. Inc., New York, N.Y., 1963).

The formation and oxidation of high-area carbon films, V. R. Deitz and E. F. MeFarlane, Proc. Fifth Carbon Conference II, 219-232 (Pergamon Press, Inc., London, England, 1963).

Pure substance and measurement, E. Wichers, Mater. Res. Stds. 1, No. 4, 314-315 (Apr. 1961).

The specific heat at constant volume of parahydrogen at temperatures from 15 to $90^{\circ} \mathrm{K}$ and pressures to $340 \mathrm{~atm}$, B. A. Younglove nad D. E. Diller, Cryogenics 2, No. 6 , 1-5 (Dec. 1962).

Radiation detectors, L. Costrell, Science 139, No. 3558, 899 (Mar. 8, 1963).

Electron spin resonance of gamma-irradiated cellulose, R. E. Florin and L. A. Wall, J. Polymer Sci. 1, Pt. A, 11631173 (1963).

The speed of light, A. G. MeNish, IRE Trans. Instr. 1-11, Nos. 3 \& 4, 138-148 (Dec. 1962). 
Fundamentals of measurement, A. G. McNish, ElectroTechnol. 53, 113-128 (May 1963).

Optimum estimators of the parameters of negative exponential distributions from one or two order statistics, M. M. Siddiqui, Ann. Math. Stat. 34, 117-121 (Mar. 1963).

Building a simple transistor tester, G. F. Montgomery, Electronics 36, No. 16, 56 (Apr. 19, 1963).

Electron microscopy studies of the surfaces of magnetic recording media, F. Nesh and D. B. Ballard, IEEE Trans. Audio AU-11, No. 1, 15-18 (Jan. 2, 1963).

A magnetic amplifier for use with diode logic, E. W. Hogue, Proc. IEEE 1963 Intern. Conf. Nonlinear Magnetics No. T-149, pp. 8.6-1 to 8.6-6 (Apr. 1963).

Kinetics of the acid-catalyzed hydrolysis of acetal in wateracetone solvents at 15,25 , and $35^{\circ}, \mathrm{R}$. K. Wolford, J. Phys. Chem. 67, 632-636 (1963).

Performance characteristics of split-type residential air-to-air heat pumps, J. C. Davis and P. R. Achenbach, Suppl. Bull. Inst. Intern. Refrigeration, pp. 1-7 (1961-1962).

Crystallographic changes with the substitution of aluminum for iron in dicalcium ferrite, D. K. Smith, Acta Cryst. 15, 1146-1152 (Jan. 1963).

Methods for the analysis of rubber and related products, M. Tryon and E. Horowitz, Handb. Analytical Chemistry, sect. 13, pp. 233-256 (McGraw-Hill Book Co., Inc., New York, N.Y., 1963)

Pressure-density-temperature relations of freezing liquid para hydrogen to 350 atmospheres, R. D. Goodwin, Cryogenics 3, 12-15 (Mar. 1963).

Nuclear magnetic resonance in metal powders at low temperatures, R. J. Snodgrass and L. H. Bennett, J. Appl. Spectry. 17, No. 2, 53-54 (1963).

Millimeter wavelength resonant structures, R. W. Zimmerer, M. V. Anderson, G. L. Strine, and Y. Beers, IEEE Trans. Microwave Theory Tech. MTT-11, 142-149 (Mar. 1963).

Lunar point-to-point communication, L. E. Vogler, Book, Technology of Lunar Exploration, Progress in Astronautics and Aeronautics 9, 533-559 (Academic Press, Inc., New York, N. Y., 1963).

Comment on "Parametric behavior of an ideal two-frequency varactor," G. F. Montgomery, Proc. IEEE 51, No. 3, 491 (Mar. 1963).

Distribution of latitude of red ares, E. Marovich and F. E. Roach, J. Geophys. Res. 68, No. 7, 1885-1888 (Apr. 1, 1963).

The following papers were published in the Proc. Intern. Conf. Ionosphere, London, 1962 (The Institute of Physics and The Physical Society, London, England):

A model of the atmosphere and the ionosphere in the $E$ and $F_{1}$ regions, R. B. Norton, T. E. VanZandt, and J. S. Denison, pp. $26-34$.

Doppler studies of the ionospheric effects of solar flares, $\mathrm{K}$. Davies, pp. 76-83.

Ionospheric variations during geomagnetic storms, S. Matsushita, pp. 120-127.

The location of the irregularities responsible for ionospheric scintillation of a radio source, H. J. A. Chivers, pp. 258-266.

Equatorial spread- $F$ motions, W. Calvert, K. Davies, E. Stiltner, and J. T. Brown, pp. 316-322.

Evidence for field-aligned ionization irregularities between 400 and $1000 \mathrm{~km}$ above the earth's surface, W. Calvert, T. E. VanZandt, R. W. Knecht, and G. B. Goe, pp. 324-329.

Experimental observations and theoretical calculations leading to a model for the lower ionosphere, R. H. Doherty, pp. 428-434.

Radio wave reflections at a continuously stratified plasma with electron collision frequency proportional to energy and arbitrary magnetic induction, J. R. Johler, pp. 436445.

Very low frequency propagation in the earth-ionosphere waveguide of non-uniform width, J. R. Wait, pp. 446-451.

United States participation in international standardization, A. T. McPherson, Mater. Res. Std. 3, No. 4, 310-311 (Apr. 1963).

A simple environmental chamber for rotating beam fatigue testing machines, J. A. Bennett, Mater. Res. Std. 3, No. 6, 480-482 (June 1963).
Standard potential of the silver-silver chloride electrode and activity coefficients of hydrochloric acid in aqueous methanol (33.4 Wt. \%) with and without added sodium chloride at $25^{\circ}$, R. G. Bates and D. Rosenthal, J. Phys. Chem. 67, $1088-1090$ (1963).

International standardization. A new responsibility of the engineer, A. T. McPherson, Natl. Acad. Sci.-Natl. Res. Council Div. of Eng. and Ind. Res. Newsletter, No. 26, 2-4 (June 1, 1963).

Path antenna gain and comments on "Properties of 400 Mc/s long-distance tropospheric circuits," W. J. Hartman, Proc. IEEE 51, 847-848 (May 1963).

Absorption and scattering of photons by deformed nuclei, E. G. Fuller, Proc. Second All-Union Conf. Nuclear Reactions at Low and Intermediate Energies, p. 419, 1960 (Russian Academy of Science, U.S.S.R., 1962).

Microwave spectrum of tertiary butyl chloride, A. Comparison of tertiary butyl structures, D. R. Lide, Jr., and M. Jen, J. Chem. Phys. 38, No. 7, 1504-1507 (Apr. 1, 1963).

Search for a slow component in alpha ionozation, Z. Bay an R. M. Pearlstein, Phys. Rev. 130, No. 1, 223-227 (Apr. 1963).

Evidence regarding the mechanism of fatigue from studies of environmental effects, J. A. Bennett, Acta Met. 11, No. 7, 799-800 (July 1963).

Dielectric friction on a rotating dipole, R. Zwanzig, J. Chem Phys. 38, No. 7, 1605-1606 (Apr. 1, 1963).

The association of plane-wave electron-density irregularities with the equatorial electrojet, R. Cohen and K. L. Bowles, J. Geophys. Res. 68, 2603-2611 (May 1, 1963).

Calorimetric calibration of the electrical energy measurement in an exploding wire experiment, D. H. Tsai and J. H Park, Exploding Wires 2, 27-107 (Plenum Press, Inc., New York, N.Y., 1962).

Quasi-equilibrium theory of mass spectra, H. M. Rosenstock and M. Krauss, Book, Mass Spectrometry of Organic Ions, pp. 1-64 (Academic Press, Inc., New York, N.Y., 1963).

Determination of differential X-ray photon flux and total beam energy, J. S. Pruitt and H. W. Koch, Book, Nuclear Physics 5, Ch. 2.8.2, pt. B, 508-553, ed. L. C. L. Yuan and C. Wu (Academic Press, Inc., New York, N.Y., 1963). Index to the communications of the ACM, 1958-1962, W. J. Youden, Comm. ACM 6, No. 3, 1-32 (Mar. 1963).

Electrode potentials in fused systems. VI. Membrane potentials, K. H. Stern, Phys. Chem. 67, 893-895 (1963).

Electron spin resonance spectra of aged, $\gamma$-irradiated polystyrenes, R. E. Florin, L. A. Wall, and D. W. Brown, J. Polymer Sci. pt. A. 1, 1521-1529 (1963).

Magnetic properties of acetinide element alloys and compounds, J. C. Eisenstein, Book, Landolt-Bornstein, 6th ed. 2, pt. 9, p. 3.236 (Springer-Velag, Berlin, Germany, 1962).

Planar twin boundary in aluminum, T. H. Orem, Trans Met. Soc. AIME 227, 786-788 (June 1963).

Radio noise anomalies in August 1958, C. A. Samson, J. Geophys. Res. 68, 2719-2726 (May 1, 1963).

Optical studies of the formation and breakdown of passive films formed on iron single crystal surfaces in inorganic inhibitor solutions, J. Kruger, J. Electrochem. Soc. 110, No. 6, 654-663 (June 1963).

The importance of environment in fatigue failure of metals, J. A. Bennett, W. L. Holshouser, and H. P. Utech, Book, Fatigue of Aircraft Structures, pp. 1-18 (Pergamon Press, Inc., London, England, 1963).

Production of Lyman alpha radiation in ion-atom collisions, G. H. Dunn, R. Geballe, and D. Pretzer, Phys. Rev. 128, No. 5, 2200-2206 (Dec. 1, 1962).

Microwave spectrum of aluminum monofluoride, D. R. Lide, Jr., J. Chem. Phys. 38, No. 8, 2027 (Apr. 15, 1963).

Some limits on the effect of coronal self-emission upon the excitation state of coronal ions, R. N. Thomas and C. Pecker, Astrophys. J. 137, No. 3, 967-980 (1962).

Oil baths for saturated standard cells, P. H. Lowrie, Jr., ISA J. 9, No. $12,47-50$ (Dec. 1962).

Two-stream plasma instability as a source of irregularities in the ionosphere, D. T. Farley, Jr., Phys. Rev. Letters 10, No. 7, 279-282 (Apr. 1, 1963). 
Performance of the barium fluoride film hygrometer element on radiosonde flights, F. E. Jones, J. Geophys. Res. 68, No. 9, 2735-2751 (May 1, 1963).

Radiation induced polymerization of propylene at high pressure, D. W. Brown and L. A. Wall, J. Phys. Chem. 67, 1016-1019 (1963).

Dielectric friction on a moving ion, R. Zwanzig, J. Chem. Phys. 38, No. 7, 1603-1605 (Apr. 1, 1963).

Survey of $\mathrm{Rb}^{85} / \mathrm{Rb}^{87}$ ratios in minerals, W. R. Shields, E. L. Garner, C. E. Hedge, and S. S. Goldich, J. Geophys. Res. 68, No. 8, 2331-2334 (Apr. 15, 1963).

Dissociation constant of pyrrolidinium ion and related thermodynamic quantities from 0 to $50^{\circ}$, H. B. Hetzer, R. G. Bates, and R. A. Robinson, J. Phys. Chem. 6\%, 1124-1127 (1963).

Introduction to the International Symposium on Equatorial Aeronomy, R. Cohen and K. L. Bowles, J. Geophys. Res. 68, 2359-2361 (May 1, 1963).

Interference fringes with long path difference using $\mathrm{He}-\mathrm{Ne}$ laser, T. Morokuma, K. F. Nefflen, T. R. Lawrence, and T. M. Klucher, J. Opt. Soc. Am. 53, No. 3, 394-395 (Mar. 1963).
Hydrogen retention system for pressure calibration of microphones in small couplers, W. Koidan, J. Acoust. Soc. Am. 35, No. 4, 614 (Apr. 1963).

Numerical computation of time-dependent properties of isotopically disordered one-dimensional harmonic crystal lattices, R. J. Rubin, J. Phys. Soc. Japan 18, Suppl. II, $63-69$ (1963).

The National Bureau of Standards: Where measurement is the central theme, C. S. McCamy, Ind. Phot. 11, No. 8, 28 (Aug. 1962).

Statistical computation of configuration and free volume of a polymer molecule with solvent interaction, J. Mazur and L. Joseph, J. Chem. Phys. 38, No. 6, 1292-1300 (Mar. 15, 1963).

* Publications for which a price is indicated are available by purchase from the Superintendent of Documents, U.S. Government Printing Office, Washington, D.C., 20402 (foreign postage, one-fourth additional). Reprints from outside journals and the NBS Journal of Research may often be obtained directly from the authors. 